\title{
Constitutive and metal-inducible protein:DNA interactions at the mouse metallothionein I promoter examined by in vivo and in vitro footprinting
}

\author{
Paul R. Mueller, Stephen J. Salser, ${ }^{1}$ and Barbara Wold ${ }^{2}$ \\ Division of Biology, California Institute of Technology, Pasadena, California 91125 USA
}

\begin{abstract}
A method of high resolution in vivo footprinting has been developed and used to survey the mouse metallothionein I (MT-I) promoter for protein : DNA interactions associated with basal-level transcription and with high-level metal-induced transcription. This promoter and its associated regulatory region is structurally complex. It contains multiple potential binding sites for metal regulatory factors and for other transcription factors, including SP1 and MLTF. In several cases potential recognition sites overlap, and the experiments reported here provide a view of which sites are utilized in vivo. These data also show how the pattern of protein : DNA contacts changes when cells are shifted from basal-level expression to metal-induced expression. The noninduced footprint pattern consists of interactions at basal elements that are thought to be responsible for the moderate transcription of this gene in the absence of added metals. These interactions remain unchanged upon metal induction. When MT-I expression is increased by exposing cells to zinc or cadmium, a new footprint pattern is observed. It includes the basal interactions and a new set of metal-dependent footprints that are positioned over all five genetically defined metal responsive elements (MREs), MRE-A-MRE-E. In addition, these data identify a sixth probable MRE, MRE-F, which displays a dimethylsulfate (DMS) footprint similar to that at other MREs.
\end{abstract}

[Key Words: Metallothionein gene; in vivo footprinting; transcription; SP1; MLTF]

Received November 16, 1987; revised version accepted March 8, 1988.

The structure of most eukaryotic promoters and associated regulatory regions is complex, consisting of an array of multiple, interdigitated sequence elements that act as recognition sites for the proteins that govern transcription (Dynan and Tjian 1985; reviewed by Maniatis et al. 1987). The task of identifying physiologically relevant sites and dissecting their individual functions is complicated by several factors: Functional binding sites are not readily discriminated from nonfunctional sites by primary sequence alone; a given segment of DNA sometimes serves as a binding site for two or more different factors; and it is often difficult to generate mutants that ablate all copies of a recognition site without also distorting the remaining sequences and their spatial relationships. In vivo footprinting studies can circumvent some of these problems by providing information on when and how recognition sites are occupied in the cell (Ephrussi et al. 1985; Giniger et al. 1985; Jackson and Felsenfeld 1985; Zinn and Maniatis 1986; Kemper et al. 1987). In this work we use in vivo footprinting of the mouse metallothionein-I (MT-I) promoter to begin to

'Present address: Department of Biochemistry, University of California, San Francisco, California, USA.

${ }^{2}$ Corresponding author. characterize DNA : protein contacts as they occur in the cell under noninducing and inducing conditions.

Metallothionein genes (MT) code for small, cysteinerich proteins that bind heavy metals, and they are present in all higher eukaryotes surveyed (reviewed by Karin 1985; Hamer 1986). Expression of the murine MT-I gene is regulated in response to several different physiological cues. Mouse MT-I is typically expressed in cultured cells at a significant basal level of about $10^{2}$ mRNAs per cell (P. Mueller, unpubl.); in the presence of added zinc or cadmium the mRNA level increases 5- to 20 -fold. This metal-dependent accumulation of MT-I RNA is primarily due to increased transcription (Durnam and Palmiter 1981; Hamer and Walling 1982). A segment of the gene containing the promoter and flanking sequences has been shown to direct both basal and induced transcription of adjacent heterologous sequences (Brinster 1982; Mayo et al. 1982; Pavlakis and Hamer 1983). DNA transfection studies of deletion mutations and synthetic promoters, together with DNA sequence data from many MT genes, have led to the identification of sequence elements that are responsible for metal induction (metal responsive elements or MREs) (Carter et al. 1984; Stuart et al. 1984, 1985; Searle et al. 1985). Other sequence elements influence the levels of 
both basal and induced expression. In vitro transcription of the related human MT-IIA gene showed that basal transcription can be increased by the addition of SP1 (Lee et al. 1987a) and other factors including AP1 and AP2 (Lee et al. 1987b; Mitchell et al. 1987), but metaldependent transcription has not yet been established in vitro, and metal dependent in vitro footprints have been confined to a single cadmium-specific site near MRE-D (Seguin and Hamer 1987).

The in vivo footprints presented here define two patterns of apparent protein:DNA contacts associated with basal level transcription and metal induced transcription of the murine MT-I gene. The footprinting strategy uses cells containing transfected, amplified MT genes to increase sensitivity and a genomic primer extension reaction to provide high resolution footprints. Our observations, taken together with existing genetic data, suggest that proteins bound constitutively at basal elements support transcription in the absence of metal induction, and also amplify the increase in transcription mediated by MREs in the presence of metals. These results focus attention on the potential for in vivo competition among factors at overlapping recognition sites, and also provide an explicit set of predictions for DNAbinding patterns expected from in vitro studies.

\section{Results}

In vivo footprinting strategy

In this work two different methods have been used to visualize in vivo protein : DNA contacts on the mouse MT-I promoter. The highest-resolution picture of these interactions was obtained by treating intact cells with dimethylsulfate (DMS). DMS methylates guanine residues at the N7 position, rendering them susceptible to subsequent cleavage with piperidine (Maxam and Gilbert 1980). Cellular proteins bound at or near specific guanines can either enhance or reduce the frequency of DMS methylation relative to the same residues in naked DNA (Gilbert et al. 1976). Because cell membranes are freely and rapidly permeable to DMS, this experiment permits detection of DNA : protein contacts in intact cells that have undergone a minimum of physiological disruption. DMS was originally used for this purpose by Giniger et al. (1985) and Ephrussi et al. (1985), and in the work presented here the procedure was adapted for mouse L cells.

The second method used to detect protein : DNA interactions is DNase I treatment of nuclei. Because DNase is a large molecule and does not freely cross the cell membrane, cells must be lysed to expose nuclei for digestion. Although such nuclei are probably not initiating new rounds of transcription (Groudine et al. 1981), it is clear from prior DNase studies of several different promoters that many specific protein : DNA contacts can be detected (Jackson and Felsenfeld 1985, 1987; Zinn and Maniatis 1986; Gimble and Max 1987). Moreover,
DNase I footprints identify protein : DNA interactions at all four residues. Therefore we use this method to complement data obtained by DMS treatment.

DNase and DMS footprints were visualized using a modification of the genomic sequencing procedure of Huibregtse and Engelke (1986). Cleaved genomic DNA was hybridized with a vast excess of a specific, end-labeled oligonucleotide primer under conditions that minimize self-renaturation of genomic DNA. The majority of the unhybridized primer was removed, and the bound primer was extended with AMV reverse transcriptase. Finally, the extension products were separated on a sequencing gel.

The in vivo footprint experiments were performed on L-cell lines transfected with a mouse MT-I-dihydrofolate reductase (DHFR) fusion gene. The gene contains $1775 \mathrm{bp}$ of the MT-I promoter and 5'-flanking sequence fused to the coding region of DHFR CDNA (Fig. 1a). This segment of the MT-I gene has been shown to direct both basal and metal-induced gene expression when transfected into cultured cells or mouse eggs (Brinster et al. 1982; Mayo et al. 1982; Pavlakis and Hamer 1983). The cell lines used here, A-0.3 and A-60, were selected because they contain multiple copies of the fusion gene, thus increasing the sensitivity of the footprint experiments. Expression of the fusion genes follows the pattern expected for MT-I regulated genes (Fig. $1 \mathrm{~b}$ and P. Mueller, S. Salser, and B. Wold, unpubl.). In the absence of added metals, A- 60 and A-0.3 cell lines display characteristic basal-level expression; upon stimulation with zinc this level increased by 5 - and 10-fold, respectively.

A DMS footprint of the MT-I promoter in A-60 cells under both noninducing and inducing conditions is shown in Figure 2. Pairwise comparison of in vitro DMS-treated DNA, ('naked' DNA, Fig. 2, lanes 5 and 10) with companion in vivo DMS-treated samples from cells grown in the presence or absence of heavy metal induction (Fig. 2, + zinc, lanes 4 and 9; no zinc, lanes 3 and 8 ) reveals several footprints in the region between -35 and -190 , and these are discussed individually in the sections that follow. By contrast, there are no detectable interactions between -30 and +20 , except a single, small, but reproducible, hypersensitivity localized just before the transcription start site. The 25-base oligonucleotides used to prime reverse transcription of cleavage products are complementary to residues -227 to -203 on the noncoding strand and to residues +47 to +23 on the coding strand. With these primers we can visualize both strands of the metal-responsive promoter sequence, as defined previously in studies of $5^{\prime}$ and $3^{\prime}$ deletion mutations (Carter et al. 1984; Stuart et al. 1984; Searle et al. 1985). Footprint experiments were performed several times on both cell lines, and DNA preparations from these DMS treatments were often assayed in multiple independent footprints. All interactions detected were highly reproducible. Densitometric traces of the autoradiograms were made, and the results are summarized in Figure 3, in which the height of the arrows is proportional to the degree of protection or enhancement at a given site. 


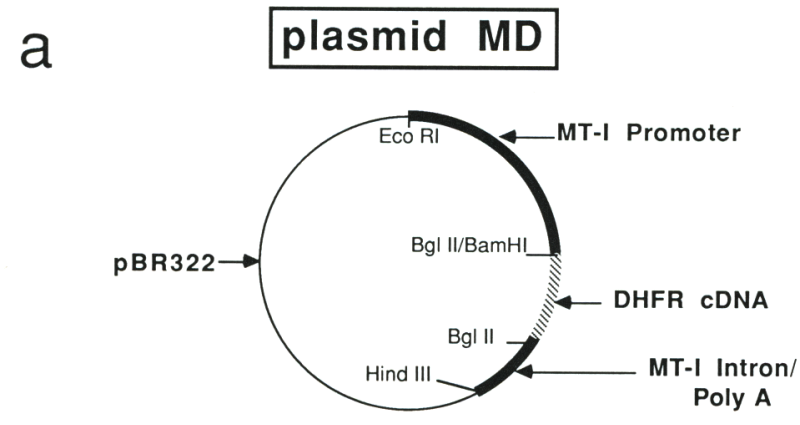

b

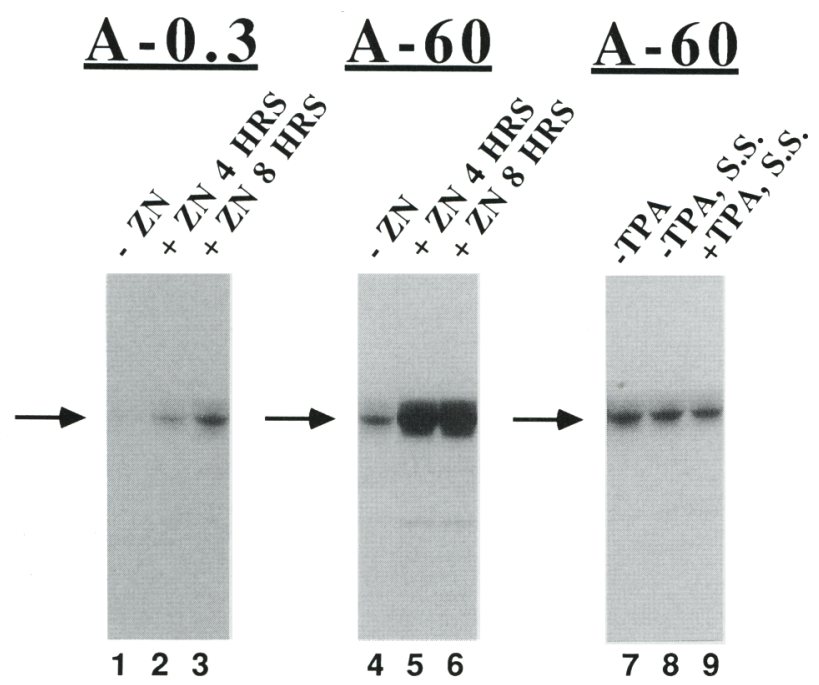

\section{SP1 binds to the MT-I promoter in vivo and in vitro}

A sequence search of the MT-I promoter reveals two good matches to the consensus recognition site for the transcription factor SP1 (Kadonaga et al. 1986; Jones et al. 1986) that are centered at -182 and -139 , but it is
Figure 1. Zinc induction of MT/DHFR. (a) Map of plasmid MD which contains $\sim 7458 \mathrm{bp}$. Thin lines are pBR322, thick solid lines are mouse MT-I, and thick striped lines are mouse DHFR. Construction is described in Materials and methods, $|b|$ MT-I/DHFR RNA measurements. RNA (15 $\mu \mathrm{g}$ total was hybridized with a uniformly labeled, 126-base riboprobe that was complementary to 80 bases $(\rightarrow)$ of the MT-promoted DHFR mRNA as per Zinn et al. (1983) and Material and methods. The endogenous DHFR is complementary to 65 bases of this riboprobe, but can not be seen on these short exposures $(\leqslant 30 \mathrm{~min})$. (Lanes 1-3), A-0.3 RNA; (lane 1), without zinc; (lane 2) $130 \mathrm{~mm}$ zinc sulfate for $4 \mathrm{hr}$; (lane 3) $130 \mathrm{~mm}$ zinc sulfate for $8 \mathrm{hr}$. (Lanes 4-9) A-60 RNA; (lane 4) without zinc; (lane 5) $130 \mathrm{~mm}$ zinc sulfate for $4 \mathrm{hr}$; (lane 6) $130 \mathrm{~mm}$ zinc sulfate for $8 \mathrm{hr}$; (lane 7) same as lane 4; (lane 8), $0.5 \%$ serum for total of $36 \mathrm{hr}$; (lane 9), $0.5 \%$ serum for total of $36 \mathrm{hr}$ and $60 \mathrm{ng} / \mathrm{ml}$ TPA for the last 12 hr.

not known whether either actually functions as an SP1 binding site. Comparison of the in vitro (Fig. 2a, lane 10) and in vivo (Fig. 2a, lanes 8 and 9| guanine ladders near base -182 on the coding strand shows a prominent in vivo footprint. Figure $2 \mathrm{~b}$ shows an enlargement of this footprint together with densitometric scans; the data are summarized in Figure 3 . The sequence within this region matches the SP1 GGCGGG core perfectly and matches the extended consensus site at 8 of 10 bases (Jones et al. 1986). For convenience, this is referred to as the SP1-A site, while the more proximal sequence at -139 is referred to as the SP1-B site. The similarity between the pattern of in vivo DMS sensitivity at SP1-A and that observed using purified SP1 in vitro is striking. The consensus in vitro pattern is predominantly on one strand, and shows protection of the first 4 bases and hypersensitivity at the 6 th and/or 7 th bases (Gidoni et al. 1984). The in vivo footprint at the SPl-A $(-182)$ site is virtually identical; the first four guanines are protected $\sim 70 \%$, and the guanine at position 7 is $\sim$ threefold hypersensitive. Also in agreement with in vitro experiments (Jones et al. 1986) are the less prominent interactions detected on the noncoding strand, with $35-40 \%$

Figure 2. $|a|$ In vivo DMS footprinting of the mouse MT-I promoter. Noncoding and coding strands are visualized by primer extension. The first and second loadings of the reaction products on a $60-\mathrm{cm}$ gel are placed on top of each other with a slight space between them. Distance from the start of transcription (TXN) is shown to the left of each strand with ' - indicating 5 ' from start and ' - ' indicating 3 ' from start. Potential sites for binding of transcription factors (based on DNA sequence and genetic data, see text) are shown by brackets to the right of each strand. A-60 cells were the source of the DNAs. (DMS) dimethylsulfate; (PIP) piperidine; (NA) naked DNA; $(-\mathrm{ZN})$, DNA methylated in vivo from noninduced cells $;(+\mathrm{ZN})$ DNA methylated in vivo from zinc-induced cells. (Lanes 1 and 5) Control samples containing in vitro purified (naked) DNA that was not treated with DMS or piperidine. (Lanes 2 and 6 ) Control samples containing in vitro purified (naked) DNA that was only treated with piperidine. (Lanes 3 and 7) DNA from noninduced cells treated with DMS in vivo and piperidine in vitro. (Lanes 4 and 9 ) DNA from cells induced with $130 \mathrm{mM}$ zinc sulfate for 4 $\mathrm{hr}$ before being treated with DMS in vivo and piperidine in vitro. (Lanes 5 and 10) In vitro purified DNA (naked) treated with DMS and piperidine in vitro. See Materials and methods for experimental details and Figure 3 for summary of data. $(b)$ Detail of SP1-A coding strand footprint. (Enlarged inset) Shorter exposure of coding strand over SP1-A region enlarged to show detail and constitutive nature of the SPI in vivo footprint. (NA) Naked DNA methylated in vitro; $(-\mathrm{ZN})$ DNA methylated in vivo from noninduced cells; $(+\mathrm{ZN})$, DNA methylated in vivo from zinc induced cells. Vertical lines beneath photo identify guanines in sequence. Densitometry plots show the initial, normalized densitometry traces of the same region enlarged above, and are superimposed on each other as indicated. Difference plots illustrate regions of footprinting in noninduced and induced cells, and were obtained by subtracting the superimposed densitometry plots from each other as indicated. Horizontal baseline represents zero difference or no footprint; traces below it represent hypersensitivity; and traces above it represent protection. These data are quantitated in Figure 3. 


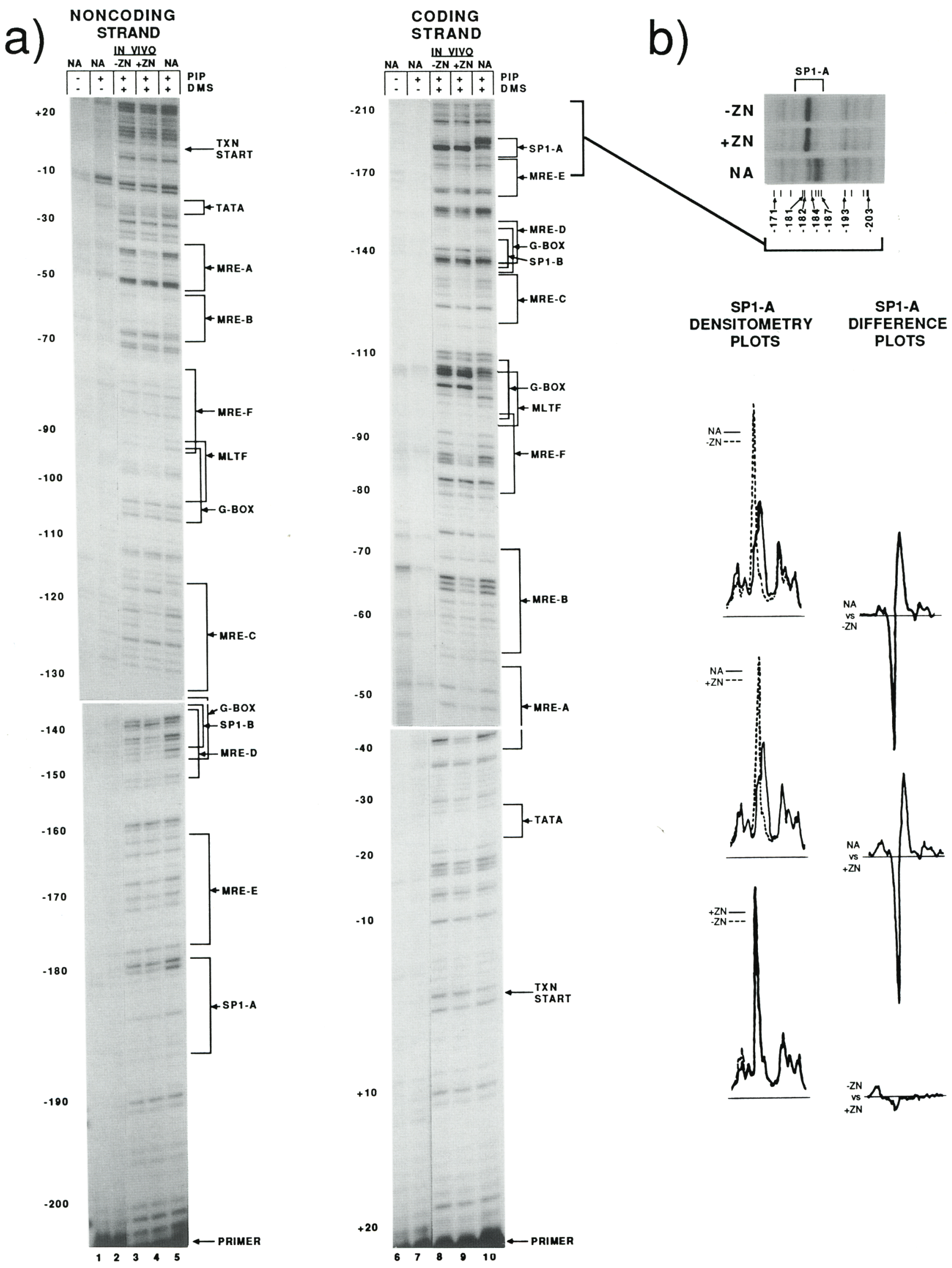

Figure 2. (See facing page for legend.) 
Mueller et al.

protection at the fifth and tenth bases. Specific guanine residues are protected from DMS attack when those residues are closely associated with a protein. If binding of a particular protein results in complete exclusion of DMS from guanines in its recognition site, $100 \%$ protection will be observed when all copies of that site are occupied continuously. Guanines -184 to -187 of the SP1-A site are $70 \%$ protected in vivo, suggesting that at least $70 \%$ of the MT-I genes are occupied throughout the 2-min DMS treatment or, alternatively, all copies in all cells are occupied $70 \%$ of the time on average. In contrast to protection from DMS attack, quantitation of hypersensitivity cannot be interpreted in a similarly straightforward fashion. It is thought that hypersensitivity to DMS
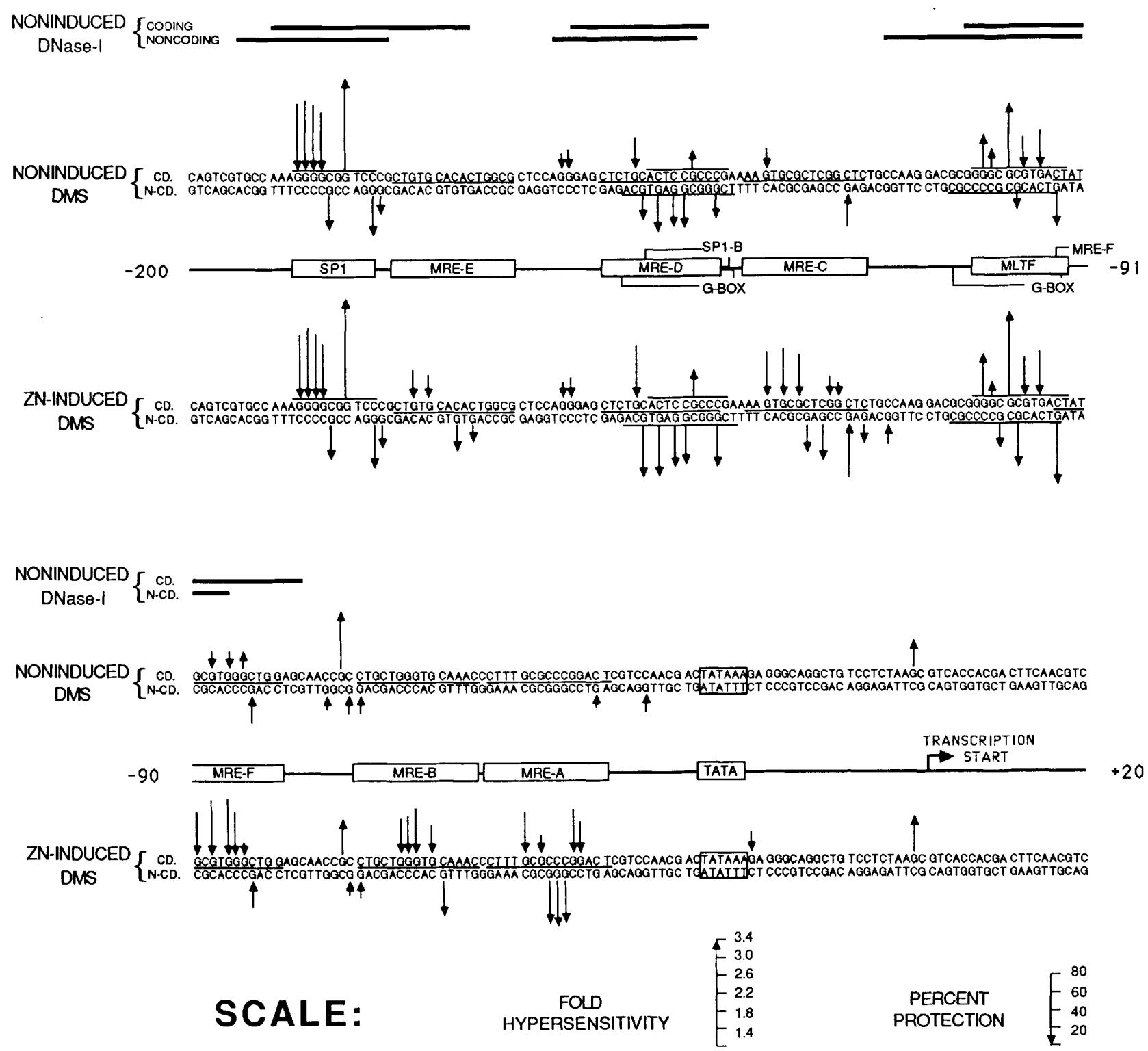

Figure 3. Summary of in vivo DMS and DNase footprinting over the mouse MT-I promoter. The sequence of both strands of the mouse MT-I promoter are shown. (N-CD) Noncoding strand; (CD) coding strand. Base pairs -200 through -91 are in the top half of the figure, and base pairs -90 through +20 are in the bottom half of the figure. Potential recognition sites are shown schematically between the noninduced and induced sequences. These sites are also localized directly on the sequences by horizontal lines: (SPI and MLTF) a line over the coding strand; (MRE) a line between the strands; (G element) a line below the noncoding strand; (TATA box) a box around both strands. Changes in methylation patterns (Fig. 2) are shown directly over the coding strand and under the noncoding strand; protections are indicated by downward pointing arrows $\mid \downarrow$, and hypersensitivities are indicated by upward pointing arrows $(\uparrow)$. See the scale at the bottom of the figure for quantitation. All protections $\geqslant 15 \%$ and hypersensitivities $\geqslant 1.3$-fold are shown. Regions of protection from DNase digestion under noninduced conditions (Fig. 4) are shown for both strands by a set of thick double lines above the noninduced DMS footprints. The sequence of this promoter is as per Glanville et al. (1981), except that an additional adenine was found at -112 (S.J. Salser, unpubl.) and is added to the sequence and numbering throughout this paper. 
results when protein : DNA interactions create a local hydrophobic environment around a target guanine (Gilbert et al. 1976). It is also possible that local changes in DNA conformation might alter DMS sensitivity (Johnsrud 1978). Given the nature of hypersensitivity, it is not possible to deduce the degree of occupancy by comparison with DMS-treated naked DNA, but it is informative to compare hypersensitivity at a given site under noninducing and inducing conditions.

In agreement with the DMS data, the SP1-A site in MT-I is protected from DNase I digestion of nuclei, indicating that protein is bound at this site. A DNase I footprint of A-0.3 nuclei is shown in Figure 4. Comparison of the DNase I pattern on naked DNA (Fig. 4, lanes 2 and 6 ) and on nuclei of noninduced cells (Fig. 4, lanes 4 and 8 ) reveals a protected region of about 20 nucleotides at the SP1-A site in nuclei. This pattern of DNase protection is in agreement with the pattern observed for SP1 binding to the SV40 promoter in vitro (Gidoni et al. 1984, 1985, and see below) and in vivo (Buchanan and Gralla 1987).

The second prospective SPl site, SP1-B, is centered at -139 . It is a 9 of 10 match with the consensus element, includes a perfect match to the GGCGGG core, and is inverted in orientation relative to the site at -182 . A DMS footprint is observed at this site, but it is much less intense than the one at the SP1-A site, and the pattern of protection and hypersensitivity is quite different from the SP1 DMS consensus pattern defined in vitro (Gidoni et al. 1984; Jones et al. 1986) and observed for the SP1-A site in vivo. The DNase I experiment corroborates the DMS data, showing a region of protection surrounding the -139 sequence (Fig. 4).

The data presented above suggest that the site at -182 is a bonafide SP1 site that is occupied in mouse L cells. The proximal site, on the other hand, shows an in vivo footprint that bears little resemblance to a simple SP1 interaction. Although the footprint at the B site does not look like a typical SP1 interaction, it remains possible that in the living cell multiple factors, including SP1, compete for this site. To determine directly if, in the absence of competing factors, bona fide SP1 binds anywhere on the MT-I promoter, an in vitro footprint experiment was done using purified SP1 (a gift of J. Kadonaga and R. Tjian.). Varying amounts of homogeneous

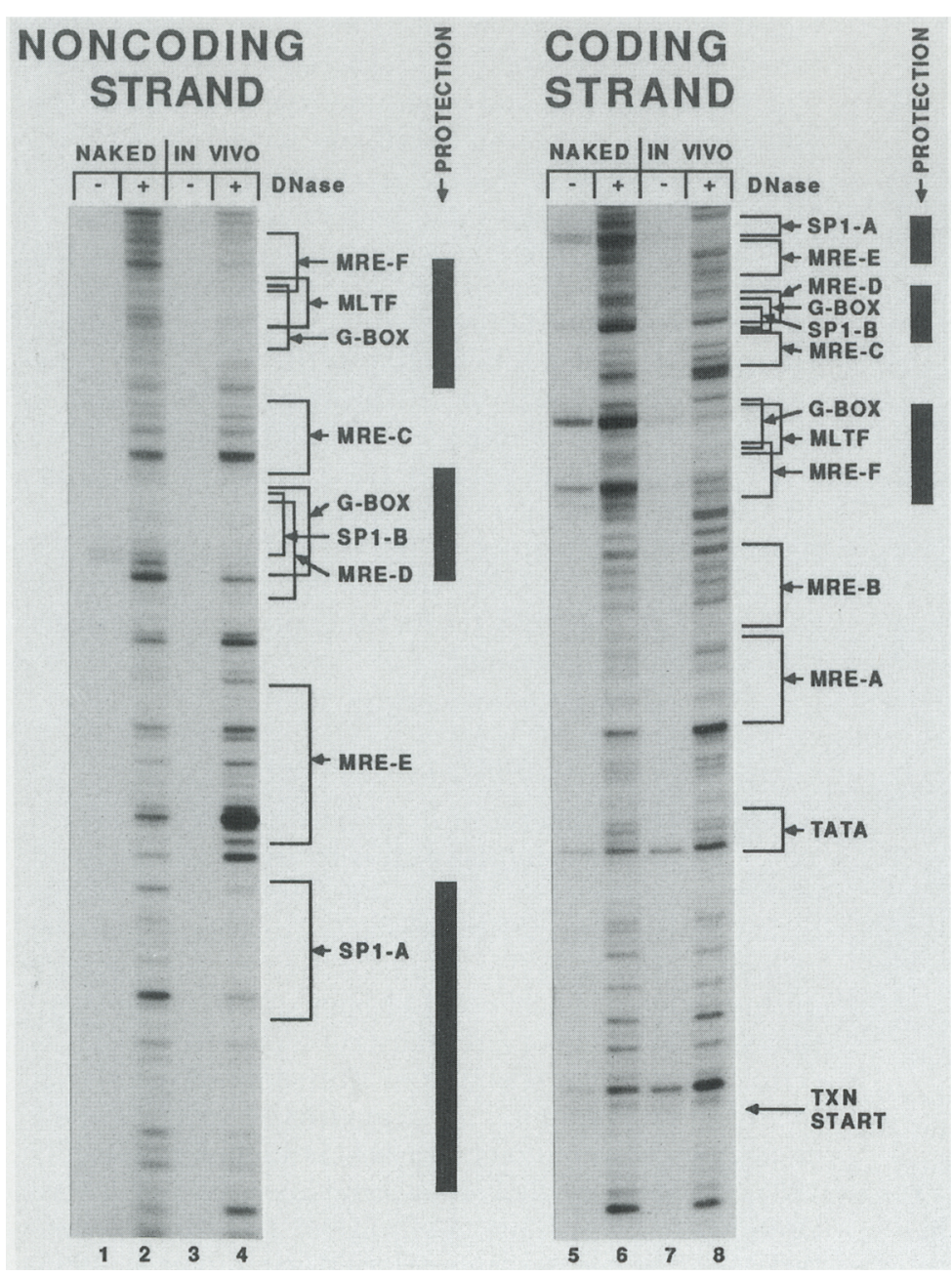

Figure 4. In vivo DNase I footprinting of the mouse MT-I promoter. The MT promoter was footprinted using DNase I as a cleaving agent as in Zinn and Maniatis (1986) and the footprint was detected by primer extension (see Fig. 2 legend and Materials and methods). The noncoding strand is shown on the right and the coding strand is shown on the left, and potential factor binding sites are indicated by brackets next to the photo. Regions of DNase protection are shown by the thick vertical lines to the left of the brackets. These were assigned by comparison of naked and in vivo patterns. The boundaries of protected regions are approximate due to typical sequence preferences in the DNase I digestion. (Lanes 1 and 5) In vitro purified (naked) DNA not treated with DNase I; (lanes 3 and 7) DNAs purified from nuclei without the addition of exogenous DNase I; (lanes 2 and 6) in vitro purified (naked) DNA treated with DNase I in vitro; (lanes 4 and 8) DNAs form nuclei treated with DNase I in vivo. These data are summarized in Fig. 3. 
SP1 were used to protect MT-I and SV40 promoter fragments from DNase I digestion (Fig. 5). The only sites protected in MT-I are the two identified above by in vivo footprinting and sequence similarity. The distal site is protected at lower SP1 concentrations than is the proximal site. The size of the region protected in both cases is $18-20$ bases, in agreement with the in vivo DNase footprint and with other in vitro SP1 footprints (Gidoni et al. 1984; Jones and Tiian 1985; Jones et al. 1986). In this experiment, the parallel SV40 footprint provides a

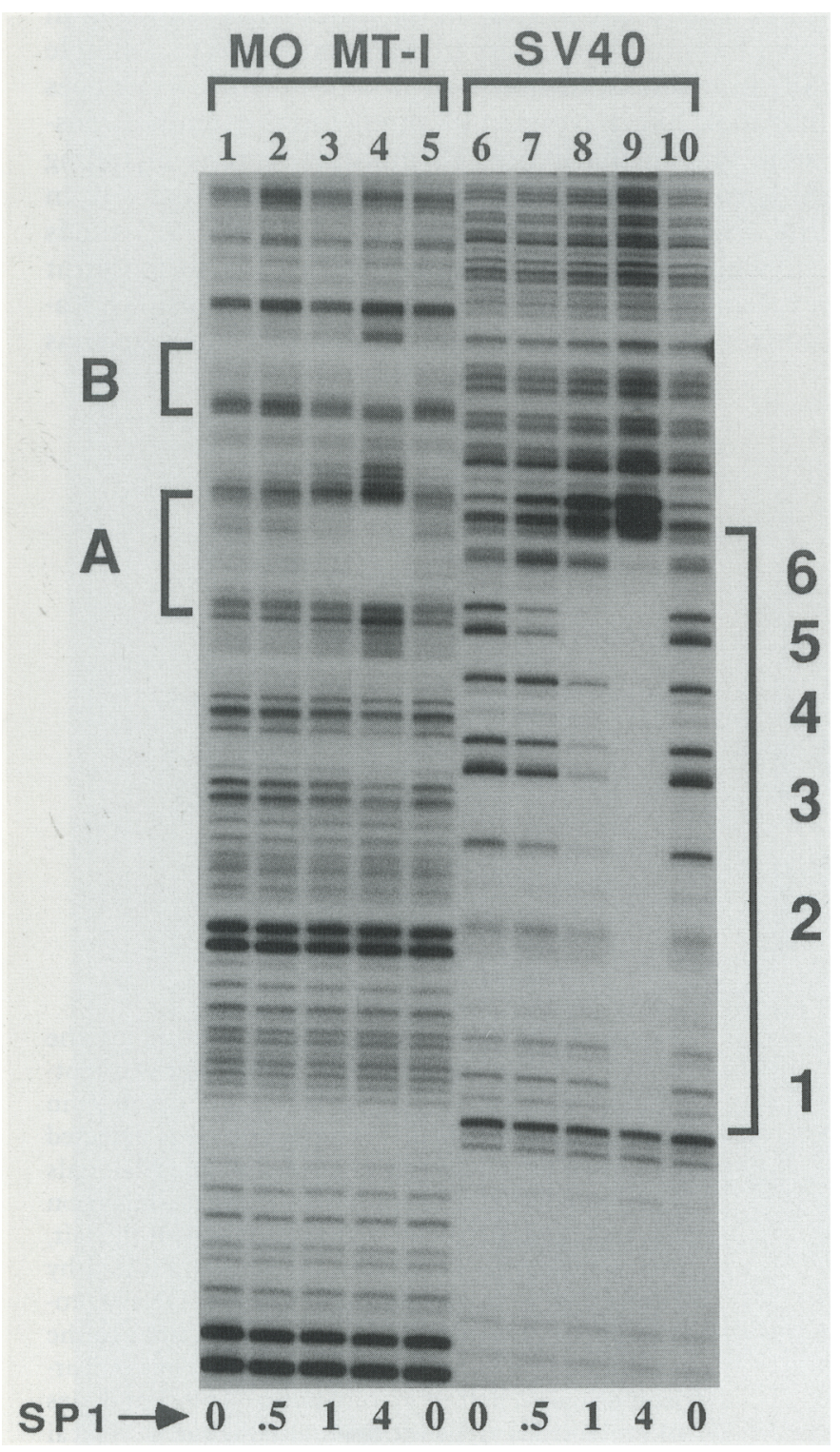

Figure 5. In vitro binding of purified SP1 on the mouse MT-I promoter. The indicated amounts of SPl (in microliters) were incubated with end-labeled MT (lanes 1-5) and SV40 (lanes 6-10) promoter sequences and the subjected to DNase I treatment in vitro (see Materials and methods). Regions of footprinting are indicated by brackets on the side of the photo. (A) MT-I SP1-A site; (B) MT-I SP1-B site (see text); and SV40 sites $1-6$ as per Gidoni et al. (1984). convenient, well-characterized standard for SP1 binding. The distal murine MT-I site binds human SP1 with an affinity between that of strong and intermediate SV40 sites, whereas binding at the proximal MT site is similar to that at weak SV40 sites. In summary, all in vivo and in vitro data suggest that the sequence at -182 of the MT promoter is occupied by a murine SP1 protein in vivo. This is consistent with the fact that deletion analyses of MT-I indicate that sequence within this region contributes to both basal and induced expression /Carter et al. 1984; Searle et al. 1985). By contrast, the proximal SP1-B site at -139 presents a more complicated picture. Apparently it is a binding site for one or more proteins in vivo, and it can serve as an SPl site in vitro, albeit a weak one. Whether SP1 is among the proteins that bind there in vivo remains uncertain (see below).

Some genetic analyses suggest that sequences which influence basal expression also amplify metal induction (Carter et al. 1984; Searle et al. 1985; Karin et al. 1984; Karin and Holtgreve 1984; Stuart et al. 1984). Is the SP1like in vivo footprint in Figure 2 affected, either qualitatively or quantitatively, by metal induction? The data in Figures 2 and 3 show clearly that there is no major change in the footprint at the SP1-A site upon zinc induction. This is best visualized by inspection of the enlarged footprint in the inset (Figure $2 b$, top), and is illustrated in the densitometric scans and difference plots (Figure 2b, bottom); and is summarized in Figure 3. The difference plots of noninduced and naked DNA or induced and naked DNA pairs show clearly the SPl footprint, and the difference plot between induced and noninduced samples reveals the striking similarity of the SP1-A footprint in cells under both conditions. The same is true for cadmium induction (data not shown). We conclude that if SP1 binding at the SP1-A site influences the level of expression during metal induction, it does not do so by simply increasing occupancy nor by a steric change that is strongly DMS sensitive. Metal induction does have a detectable effect on the DMS- sensitivity of some guanines in the second potential SP1-B site located at -139 , but the juxtaposition of this site with possible binding sites for other proteins may be responsible (see Discussion).

\section{MLTF binds the murine MT-I gene in vivo}

Another prominent set of hypersensitive and protected guanine residues comprise a clear in vivo DMS footprint between positions -94 and -105 (Figs. $2 a$ and 3). This region is also protected from DNase I digestion in nuclei of noninduced cells (Fig. 4). Inspection of the sequence in this region revealed a 9 of $12 \mathrm{bp}$ match to the recognition site of the major late transcription factor (MLTF), a cellular factor that was first identified by its activity at the major late promoter of adenovirus 2 (Ad 2) (Carthew et al. 1985; Miyamoto et al. 1985; Sawadogo and Roeder 1985; Chodosh et al. 1986). Comparison of our in vivo DMS footprint with the in vitro DMS footprint for purified MLTF at the Ad2 promoter (Miyamoto et al. 1985) 
shows that the patterns of protection from methylation are very similar (Fig. 6). Moreover, recent in vitro footprinting experiments show that purified MLTF binds at this site in the murine MT-I promoter /Carthew et al. 1987). This region also contains a weaker sequence similarity (5 of 7) to the recognition site of transcription factor AP1, which has been shown to function in the human MT-IIA gene (Lee et al. 1987a,b). AP1 activity can be modulated by the phorbol ester TPA (Angel et al. 1987), and genes containing an AP1 element can be induced by treating cells with TPA (Angel et al. 1986, 1987; Imbra and Karin 1987). In an initial experiment, we tested whether expression of the MT-I genes in our A-60 cells is elevated in response to TPA. The data in Figure $1 \mathrm{~b}$ show that the steady-state level of RNA was not affected by TPA treatment. This experiment is not decisive, but when the result is considered together with divergence from the consensus site, it suggests that AP1 is not responsible for the footprint centered around -100 . We conclude that murine MLTF is bound to the MT-I gene in vivo at the site between -93 and -104 . Our data also show that there is little change in occupancy at this site upon metal induction (Fig. 2a and summarized in Figs. 3 and 6).

\section{Metal dependent protection of MRE sequences}

All MT genes contain multiple copies of MREs /Carter et al. 1984; Karin et al. 1984; Stuart et al. 1984, 1985; Anderson et al. 1986; Maroni et al. 1986). When two or more MREs are inserted upstream from a basal promoter, they can confer metal responsiveness upon that promoter (Searle et al. 1985; Stuart et al. 1985). MREs are a family of moderately similar sequence of about 15 bp that are related to a rather loosely defined consensus sequence: CTNTCC(A/G)CNCGGCCC, in which the underscored bases comprise the core consensus element. The five MREs of the mouse MT-I gene have been designated MRE-A through MRE-E, with MRE-A being closest to the start of transcription and MRE-E most distant (Stuart et al. 1984).

In noninduced cells, MREs A-E display a DNase I pattern that is essentially identical with naked DNA (Fig. 4), and they show very little protection from in vivo DMS treatment (Figs. 2, 3, 7), with the exception of MRE-D, which is discussed below. Upon stimulation with zinc, all of the MREs show protection of most guanines in vivo. The degree of protection ranges from $20 \%$ to $65 \%$ and corresponds well with the ability of each individual MRE to confer metal response upon a heterologous promoter (Stuart et al. 1985). For example, MRE-E is unable to confer metal inducibility on the HSV-TK promoter, and it shows very little DMS protection here. The converse is true for elements A and C, which are more highly protected and are also potent metal response elements in synthetic promoters. Detectable protection from DMS is dependent on zinc induction at all sites except MRE-D, where metal treatment enhances a preexisting low-level protection. Slight

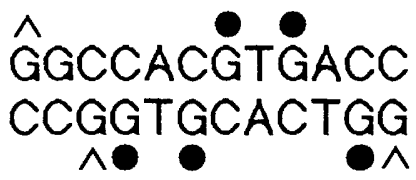

MLP Ad2
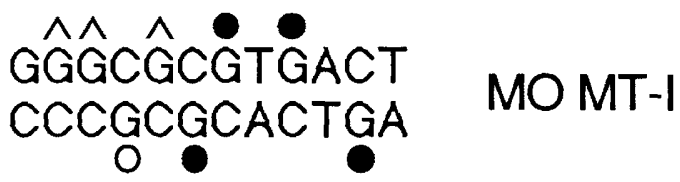

Figure 6. Comparison of in vitro and in vivo MLTF DMS footprints. The in vitro DMS footprint pattern over the MLTF site between -63 and -52 in the major late promoter of adenovirus 2 (Miyamoto et al. 1985) is compared to the in vivo DMS footprint pattern over the MLTF site between -104 and -93 in the mouse MT-I promoter (Fig. 2a and 3). Carrots ( 1 , hypersensitivity; filled circles $(\bullet)$, protection under noninduced and $\mathrm{Zn}$-induced conditions; and open circles $(0)$, protection only observed under induced conditions.

hypersensitivity at the last three or four positions of most MREs is also observed. Figure 7 contains a summary of DMS footprints at MREs together with representative densitometry. A simple interpretation of the footprint pattern is that in the noninduced state MREs are not occupied, but upon metal induction they are protected due to the binding of positive-acting metal-responsive factors (MRF). This agrees with data from in vivo competition studies which show that the limiting factors in metal induction act in a positive fashion (Seguin et al. 1984; Scholer et al. 1986; Mueller et al., in prep.). While this is the simplest view consistent with all data, the absence of a footprint under noninducing conditions must be interpreted cautiously, because it is expected that some interactions will escape detection, especially if they are relatively unstable or transitory.

Virtually all metal-dependent DMS protections can be accounted for by MREs A-E, with the noteworthy exception of a cluster of protected residues centered around -87 (Figs. 2 and 3 ). This region contains a sequence that is moderately related to the MRE consensus: It matches at 9 of 15 positions overall, but possesses greater similarity in the MRE 'core', in which 4 of 5 bases agree. The DMS pattern is also quite similar to that at the other MREs (Fig. 7). Some deletion analyses of this gene are consistent with the sequence functioning as a hitherto unidentified MRE (Searle et al. 1985). Although these mutation data are not decisive, the sequence similarity, footprint pattern, and deletion data lead us to identify it provisionally as MRE-F. One potentially interesting distinction between MRE-F and the other MREs is that it appears to be less efficiently protected from DMS when cells are treated with cadmium than when they are induced with zinc /data not shown), whereas the others are affected identically by both inducers. 
Mueller et al.

\section{Footprinting amplified and transfected genes}

In these experiments we have shown that in vivo footprinting studies can be executed successfully on transfected, amplified genes, and this approach should be gen- erally applicable to promoters other than MT. It requires $\geqslant 15$ functional copies of the promoter per mammalian genome (S. Salser, unpubl.), although single-copy genes should be readily accessible in smaller genomes. In this study, cell lines containing sets of active genes were de-
NONINDUCED

CTTTGCGCCCGGACT
GAAACGCGGGCCTGA

MRE-A

ZN-INDUCED

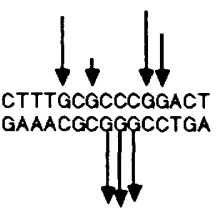

GTTTGCACCCAGCAG
CAAACGTGGGTCGTC

MRE-B

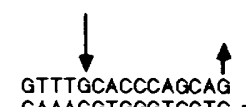

GTTTGCACCCAGCAG
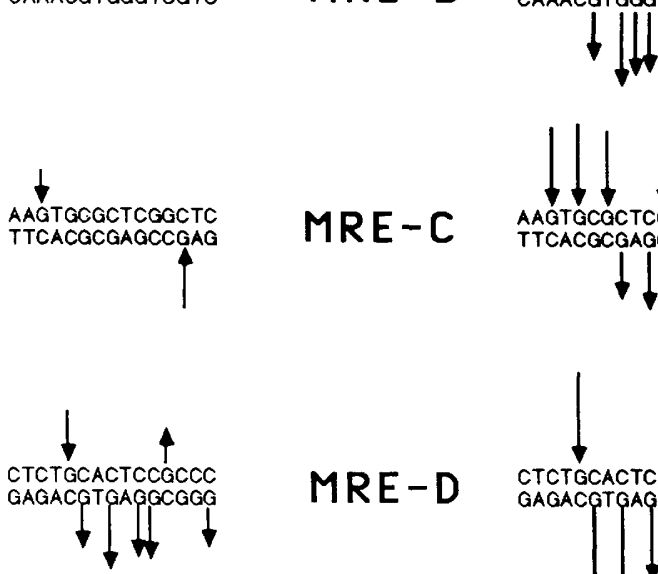

CTGTGCACACTGGCG GACACGTGTGACCGC

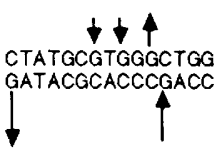

MRE-C

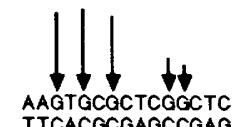

AAGTGCGCTCGGCTC

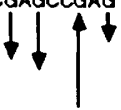

MRE-D

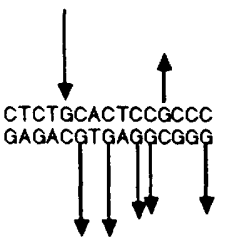

MRE-E

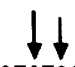

CTGTGCACACTGGCG GACACGTGTGACCGC

GACACQTGTGACO

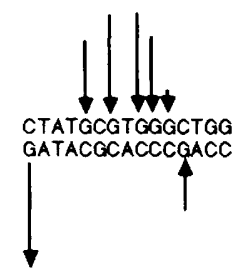

$\underset{\text { HYPERSENSITIVITY }}{\text { FOLD }}\left[\begin{array}{l}2.6 \\ 2.2 \\ 1.8 \\ 1.4\end{array}\right.$

MRE-F

\section{MRE-B CODING STRAND}

\section{DENSITOMETRY PLOTS DIFFERENCE PLOTS}
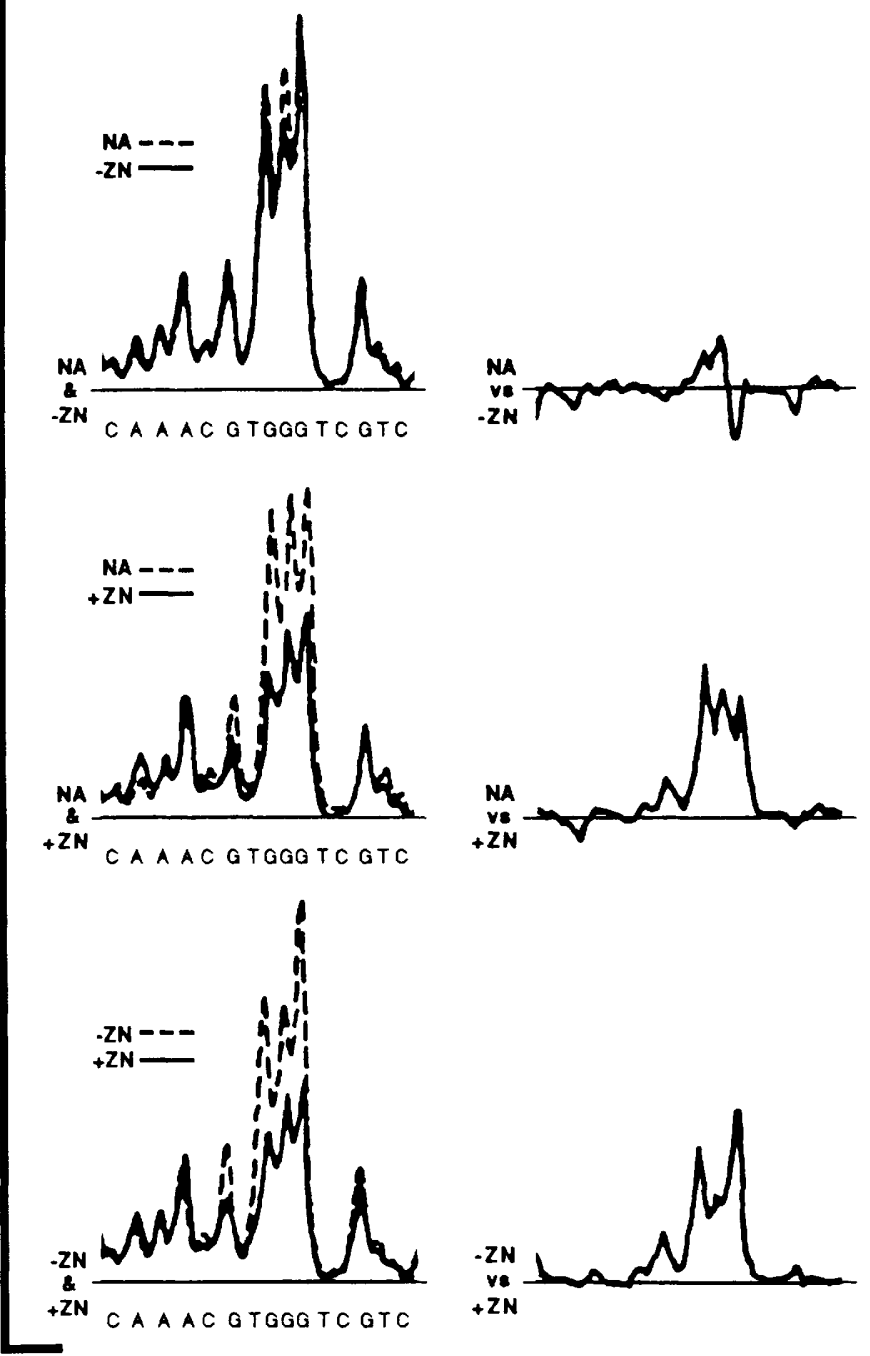

Figure 7. Summary of in vivo DMS footprint patterns over MREs. The five previously identified MREs A-E (Stuart et al. 1984) are shown along with the potential MRE-F. All MREs are oriented with the coding strand on top as they appear in the promoter except MRE-B, which is inverted here to allow comparisons of the footprint patterns. Quantitation of DMS footprints under noninduced and Zn-induced conditions was performed as described in Materials and methods and is indicated by downward pointing arrows $(\downarrow)$ for protection, and by upward pointing arrows $(\uparrow)$ for hypersensitivities. Scale is at bottom of figure. An example of MRE densitometry is shown for the coding strand of MRE-B on the right half of the figure. The initial, normalized plots are superimposed pairwise as indicated and the corresponding difference plots are shown on the right. Beneath the densitometry plots is the coding strand sequence of MRE-B. (NA) In vitro purified DNA (naked); $(-\mathrm{ZN})$ in vivo DNA, noninduced; $(+\mathrm{ZN})$ in vivo DNA, $\mathrm{Zn}$-induced. 


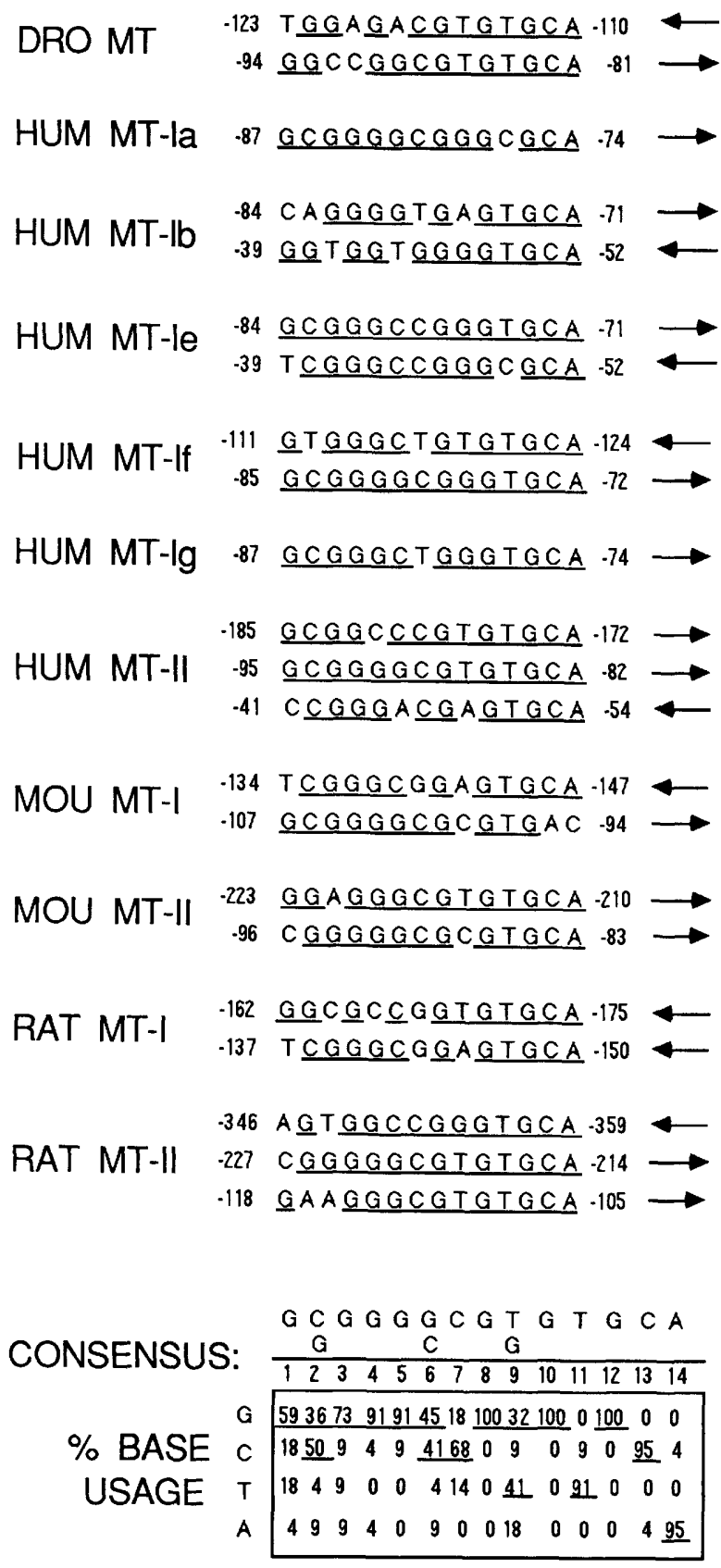

rived by amplification of a chimeric MT-DHFR construct, but multiple-copy transformants could be equally useful. As in other transfection studies, it is necessary to select for footprinting transformants that show proper expression. Our cell lines were checked to ensure metal induction (Fig. 1b), and basal-level expression characteristic of the native MT gene was maintained by continuous selection for DHFR expression (see Materials and methods). From the $70 \%$ and $65 \%$ protection at SP1 and MRE sites, respectively, it is clear that a large fraction of the transfected MT promoters in these cells is accessible to binding by cellular factors. It is worth noting that
Figure 8. Evolutionary conservation of $\mathrm{G}$ elements in higher eukaryotic metallothioneins. Shown are the $22 \mathrm{G}$ elements found in $11 \mathrm{MT}$ promoters, and the consensus we have derived. General conservation of $G$ rich regions has been noted previously (Karin 1984) and designated variously as a basal level enhancer (BLE) (Scholer et al. 1986), a part of the BLE (Karin et al. 1987), or a G-rich sequence (Seguin et al. 1986). Numbers on either side of the G elements indicate their location in the promoters relative to the transcriptional start site. Arrows to the left of the sequences indicate the orientation of the elements in their promoter. All of the elements have been displayed in the orientation of the consensus for comparative purposes. The consensus along with the percent base usage is indicated at the bottom of the figure. Sources: Drosophila MT (Maroni et al. 1986); human MT-Ia (Richards et al. 1984); human MT-Ib (Heguy et al. 1986); human MT-Ie (Schmidt et al. 1985); human MT-If and human MT-Ig (Varshney et al. 1986); human MT-II (Karin et al. 1987); mouse MT-I (S.J.S. unpubl., see Fig. 3 legend and Glanville et al. 1981); mouse MT-II (Searle et al. 1984); rat MT-I (Andersen et al. 1986); rat MT-II (R.D. Andersen, unpubl. 1986, NIH data base).

transfected target genes sometimes present specific limitations. For example, a peculiarity of mouse MT-I is that the endogenous gene is inducible by glucocorticoids, but no cloned DNA segment that retains this property upon transfection into cultured cells or into transgenic mice has been identified (Mayo et al. 1982; Pavlakis and Hamer 1983; Palmiter et al. 1982). In agreement with these observations, we found that the MT-DHFR genes are not induced by dexamethasone, and therefore we did not attempt to footprint following hormone treatment.

Although in vivo footprinting is an effective method for visualizing a subset of protein : DNA interactions on a given gene, it is not expected that all protein : DNA contacts will be detected by this assay. For example, we do not observe significant footprinting over or near the TATA box (Figs. 2 and 3), even though these genes are being transcribed at a physiologically significant rate. This is also the case in several other in vivo footprinting studies of actively transcribing genes (Zinn and Maniatis 1986; Kemper et al. 1987). Nevertheless, it is clear that a set of proteins in nuclear extracts do bind in vitro in other TATA containing genes (Davison et al. 1983; Parker and Topol 1984; Sawadogo and Roeder 1985), and previous genetic experiments have shown these sequences to be important for efficient MT-I transcription (Carter et al. 1984). Perhaps the interactions that are observed in vivo at upstream elements are significantly more stable than are those that occur at the TATA sequence. In spite of these constraints, it is clear that we have successfully identified interactions at MRF, SPl, and MLTF binding sites in the murine MT-I promoter, and genetic analyses (Carter et al. 1984; Stuart et al. 1984; Searle et al. 1985) support the functional significance of these interactions. Based on these results, we suggest that it should now be efficient to survey other complex control regions in this way at an early stage in their characterization to focus subsequent mutagenesis or in vitro protein binding studies. 


\section{Discussion}

We have used in vivo genomic footprinting with DMS and DNase I to observe DNA : protein interactions at the MT-I promoter (Figs. 3 and 7). These experiments led to definition of two sets of probable protein : DNA interactions as they occur in cells under noninducing and inducing conditions. The results obtained allowed us to identify a new metal-responsive element, to limit the possible mechanisms for interaction between basal-level elements and metal-responsive elements, and to begin to resolve how overlapping, and thus potentially competing, recognition sites are actually used.

It is interesting to compare the pattern of in vivo protection at MREs with in vitro studies of Seguin and Hamer (1987). They observed a cadmium-dependent Exo III footprint at MRE-D when MT-I DNA was incubated with a nuclear extract. Our results differ from their in vitro data in two respects. First, they detect binding only in the presence of cadmium but not in the presence of zinc, whereas we find similar in vivo footprints with both metals at MREs A-E. Second, they observe binding at just one MRE, whereas we see footprints at MREs A-E and $F$. The general pattern of in vivo interactions we have observed is, however, in close agreement with in vivo studies reported recently by Herschman and colleagues (Anderson et al. 1987) for the related rat MT-I gene. We do not know the basis for the differences between in vivo and in vitro results, although it is interesting that our data find MRE-D to be the only metal response element showing a detectable footprint in the absence of added metal (Fig. 7). It may also be relevant that MRE-D $(-150$ to -136$)$ overlaps the potential binding site SP1-B (-143 to -134$)$, as discussed below.

\section{Overlapping recognition sites and possible competition among factors}

The presence of overlapping potential binding sites at the MRE-D/SP1-B region raises the possibility of competition among several different factors. DNA sequence data alone do not provide enough information to predict which factors, if any, will be bound at this site in the cell. The in vitro SPl footprint data (Fig. 5) establish that this sequence can serve as a SPI binding site in the absence of competing factors, which leaves open the possibility that it may function as a SPl site in vivo. The in vivo DNase (Fig. 4) and DMS (Fig. 2) footprints show that this region is occupied by factors in $\mathrm{L}$ cells, but the absence of the characteristic SP1 DMS footprint pattern makes it unlikely that SPl is responsible. Another possibility is that, in both the induced and noninduced state, there is significant binding of metal-responsive factors at this site. This alternative is supported by the pattern of DMS footprinting. The DMS pattern at MRE-D in noninduced cells is qualitatively similar to that at other functional MREs after metal induction. The induced pattern at MRE-D is quantitatively increased upon metal induction but not qualitatively changed from its basal pattern. It is interesting that MRE-D is the most effective MRE when present in multiple copies in a synthetic promoter (Stuart et al. 1985) and is also the only MRE to show metal-dependent protein binding in vitro (Seguin and Hamer 1987).

For the case of the MRE-D/SP1-B region, our working model is that in L cells the balance between active SPI and MRFs favors binding by MRF, but this may not be the case in other cell types or under different physiological conditions. The notion of in vivo competition for overlapping sites has some appeal because it provides a potentially sensitive mechanism for regulating gene expression in different cell types or tissues in response to modest differences in relative levels of participating factors. Small genetic changes can also tip the balance between two binding sites, and such changes may be important in the evolution of different patterns of expression. An inadvertent experimental example was provided when Stuart et al. (1985) placed oligomers containing the MRE-D overlap region in front of a truncated HSV-TK promoter containing only a TATA element. The wild-type MRE-D region made TK expression metal inducible. Surprisingly, they found that if the oligomer was modified so as to make it a better match to the SP1 consensus without disrupting the MRE, the gene was no longer inducible by metals, but exhibited a 10 -fold elevation in basal expression. Competition among factors for binding in this region may also contribute to the multiplicity of protein : DNA complexes observed as distinct electrophoretic species when DNA is incubated with crude nuclear extracts (Seguin and Hamer 1987).

The phenomenon of overlapping, potentially competing recognition sites is probably not confined to the MRE-D/SP1-B region. All higher eukaryotic MT genes for which sequence data are available contain one or more copies of a conserved 14-bp G-rich sequence, and from 22 examples we have derived a consensus element G(C/G)GGG(C/G)CG(T/G)GTGCA (Fig. 8). A function has not yet been defined for this sequence feature, so it is simply referred to here as the $\mathrm{G}$ element or $\mathrm{G}$ box. Murine MT-I contains two of these elements: one centered around -140 , the other centered around -100 . Like other MT G-boxes, these overlap other potential recognition sites. The site centered at -140 overlaps the MRE-D and SP1-B sites, and the element centered at -100 overlaps the MLTF site. In other MT genes (for example, human MT-IIA, human MT-IA, mouse MT-II, and Drosophila MT) G elements overlap potential SPI and MRE sites. Our footprinting data did not detect interactions specifically attributable to G elements, and existing mutational studies assayed in various cell lines have also failed to detect a specific G-box function. On the other hand, the presence of G-elements in all MT genes, together with their substantial sequence similarity, suggest that they are important enough to demand evolutionary conservation, probably because they serve as recognition sites for one or more factors. It seems possible that the $G$ elements may be required in a physiological context that has not been tested by the transfection assays and footprinting studies. 


\section{Interaction of MREs and basal elements}

Although multiple MREs are sufficient to direct metalinducible transcription from heterologous promoters, the absolute level of expression depends on additional non-MRE upstream elements. For example, Stuart et al. (1985) found that in the context of a synthetic promoter, SP1 elements amplify the MRE-mediated response, and promoter mutations generally support this view. The effect is not simply additive, but is synergistic. A survey of different MT regulatory regions shows that the theme of multiple MREs combined with several potential basal elements is common, but there is considerable flexibility in basal element identity and sequence organization. This suggests that the capacity of basal element factors to enhance MRE activity is a general property shared by several factors including SPI (mouse MT-I, human MT-IIA), APl (human MT-IIA), and MLTF (mouse MT-I).

How do basal elements amplify metal induction? The constitutive occupancy of SP1 and MLTF sites in vivo rules out one straightforward mechanism for amplifying metal- dependent expression: Active MREs do not function by simply increasing the efficiency of factor binding at basal element sites. The possibilities that remain fall into two classes. MREs and basal elements both may act by increasing directly the rate of initiation. Alternatively, basal elements might alter the rate of metal-induced transcription by increasing the accessibility of DNA to factors that do govern initiation--possibly MREs. These different functions for basal elements are not easily distinguished by standard cell transfection assays or by current in vitro transcription systems, although it should now be possible to introduce appropriately mutated promoters and observe how ablation of one or more of the basal elements affects the in vivo protein : DNA interactions at MREs.

\section{Materials and methods}

\section{Plasmid construction}

Plasmid MD was constructed from the mouse MT-I genomic sequences of pEE-3.8 (a gift from R. Palmiter) and the DHFR sequences of SV3-DHFR (Southern and Berg 1982). The MT-I promoter fragment used in this plasmid contains $\sim 1775$ bp of 5 ' nontranslated sequences between EcoRI and BgIII. The BgIII site ends $8 \mathrm{bp}$ on the $5^{\prime}$ side of the MT translation start. The $3^{\prime}$ MT fragment contains the complete second intron and poly(A) addition site of MT-I as an AluI-HindIII fragment, with the AluI site converted to a BglII site. These fragments were inserted into pBR322 to create pMT-33. The coding region of DHFR, along with $60 \mathrm{bp}$ on the $5^{\prime}$ side of and $80 \mathrm{bp}$ on the $3^{\prime}$ side of the translation start and stop respectively, was removed from SV3-DHFR as a FnuDII-BglII fragment and inserted into the BgIII site of pMT-33 after addition of a BamHI linker at the FnuDII site.

\section{Cell culture}

Murine cell lines A-0.3 (formerly KTO-A, Kim and Wold 1985) and A-60 were gifts from S. Kim, and were adapted for growth in dialyzed calf serum. These lines were maintained in Dulbecco's modified Eagle's medium (DME) supplemented with $10 \%$ dialyzed calf serum (Gibco), $100 \mathrm{U} / \mathrm{ml}$ penicillin $\mathrm{G}, 7.5$ $\mathrm{U} / \mathrm{ml}$ streptomycin, $4 \mu \mathrm{g} / \mathrm{ml}$ azaserine, $15 \mu \mathrm{g} / \mathrm{ml}$ adenine, and $3 \times$ nonessential amino acids. Dialysis of the serum increased the induction ratio of MT genes $\sim$ twofold by lowering the basal level of expression (P.R. Mueller, unpubl.). A-0.3 and A-60 were further supplemented with $0.3 \mu \mathrm{M}$ and $60 \mu \mathrm{M}$ methotrexate (MTX), respectively. The presence of MTX did not influence the expression or induction of the MT genes (data not shown). A- 0.3 and A- 60 contain 100 and 700 copies of pMD, respectively (J. Jong, unpubl.).

\section{RNA preparation and measurement}

Cells were $\sim 70 \%$ confluent before induction. Four or $8 \mathrm{hr}$ prior to harvesting the RNA, fresh media were added to the plates with or without $130 \mu \mathrm{M}$ zinc sulfate. Prior to TPA (12-O-tetradecanoyl-phorbol-13-acetate) inductions, cells were washed with PBS and transferred to media containing $0.5 \%$ dialyzed calf serum, without azaserine or methotrexate (MTX) for $24 \mathrm{hr}$. TPA (in ETOH) or an equivalent volume of ETOH (14.4 $\mu \mathrm{l}$ ) was then added to the serum-starved media for an additional $12 \mathrm{hr}$. Final concentration of TPA was $60 \mathrm{ng} / \mathrm{ml}$. Total RNA for each condition was prepared from two $150-\mathrm{cm}$ plates according to the method of Chirgwin et al. (1979), as modified by Ngai et al. (1984). RNA was further purified by extraction with phenol/ Sevag and precipitation with isopropanol and then ethanol. Subsequent treatment with RNase-free DNase had no effect on RNA quantitation (data not shown), so this was not done routinely.

RNase protection was performed as described by Zinn et al. (1983) and modified by Kim and Wold (1985). Fifteen micrograms of total RNA was hybridized with a molar excess $112 \mathrm{ng}$, or $280 \mathrm{fmoles}$ ) of labeled probe of specific activity $7 \times 10^{8} \mathrm{cpm} /$ $\mu \mathrm{g}$. The probe used protects the DHFR sequences in the construct and the endogenous DHFR, but the endogenous signal is much weaker than the strong construct signal and cannot be seen on short exposures. Longer exposures of RNA experiments performed on the parental cell lines show that the protected endogenous band is $\sim 15$ bases shorter than the protected construct band (P. Mueller, unpubl.). This is consistent the with major transcriptional start site of mouse DHFR (Farnham and Schimke 1986). Gel slices containing the protected probe were excised and counted for quantitation.

\section{In vivo and in vitro DMS/piperidine cleavage of DNA}

Cells for in vivo footprinting were treated identically to those used for RNA measurements. After $4 \mathrm{hr}$ with or without 130 $\mu \mathrm{M}$ zinc sulfate, the media was replaced with media containing $1 \mu \mathrm{l} / \mathrm{ml}$ DMS (DMS was added immediately before use). This replacement media also contained $130 \mathrm{~mm}$ zinc sulfate, if appropriate, and was prewarmed to $37^{\circ} \mathrm{C}$ in a $4 \% \mathrm{CO}_{2}$ environment. The DMS was allowed to react with the cells for 2 min, at which time the DMS-containing media was removed and the plates immediately were rinsed once with $37^{\circ} \mathrm{C}$ PBSA and subsequently washed $3 \times$ with $37^{\circ} \mathrm{C}$ PBSA for $30 \mathrm{sec}$ with gentle shaking. Cells were lysed and scraped from each plate in $1.5 \mathrm{ml}$ of DNA harvest buffer [ $1 \mathrm{~mm}$ Tris (pH 7.5), $400 \mathrm{mM} \mathrm{NaCl}, 2 \mathrm{~mm}$ EDTA, $0.2 \%$ SDS, $0.2 \mathrm{mg} / \mathrm{ml}$ proteinase $\mathrm{K}$ ], and this mixture was incubated with occasional mixing for an additional $3-5 \mathrm{hr}$ 
at $37^{\circ} \mathrm{C}$. DNA was extracted once each with phenol, phenol/ Sevag, and Sevag; and twice with ether. The DNA was then precipitated once with isopropanol and once with ethanol before resuspending it in $10 \mathrm{~mm}$ Tris $(\mathrm{pH} 7.5), 1 \mathrm{~mm}$ EDTA. The final nucleic acid concentration was $1-1.5 \mathrm{mg} / \mathrm{ml}$, of which $50-60 \%$ was DNA. To precipitate the in vivo methylated DNA in parallel with the in vitro methylated DNA (see below), 200 $\mu \mathrm{l}$ of this mixture was mixed with $50 \mu \mathrm{l}$ of $1.5 \mathrm{M}$ sodium acetate $(\mathrm{pH} 7.0), 1 \mathrm{M} \beta$-mercaptoethanol, $100 \mu \mathrm{g} / \mathrm{ml}$ yeast tRNA, and $750 \mu \mathrm{l}$ of ethanol. The pelleted DNA was washed once with $75 \%$ ethanol before being suspended in $200 \mu \mathrm{l}$ of $1 \mathrm{M}$ piperidine, and then heated to $90^{\circ} \mathrm{C}$ for $30 \mathrm{~min}$. Piperidine treatment cleaves DNA at methylated guanines and eliminates contaminating RNA by base hydrolysis. Piperidine was removed by vacuum followed by two cycles of washing and precipitation.

DNA for in vitro DMS treatment (naked) was prepared identically, except the in vivo DMS treatment step was omitted. This DNA was methylated in vitro by adding $0.9 \mu \mathrm{l}$ of DMS to $200 \mu \mathrm{l}$ of DNA $(\sim 1 \mathrm{mg} / \mathrm{ml})$ for $30 \mathrm{sec}$ at room temperature. This DMS condition was empirically determined to match the in vivo DMS conditions. Under methylation would show a general underrepresentation of lower-molecular-weight bands and overrepresentation of high-molecular-weight bands. The converse is true for overmethylation. Such mismatches in methylation conditions do not, however produce specific local patterns of protection or hypersensitivity that would be easily mistaken for protein : DNA footprints. The reaction was stopped with $50 \mu$ l ice-cold stop buffer [ $1.5 \mathrm{M}$ sodium acetate $(\mathrm{pH} 7.0), 1$ M $\beta$-mercaptoethanol, $100 \mu \mathrm{g} / \mathrm{ml}$ of yeast tRNA] and $750 \mu \mathrm{l}$ of ethanol chilled to $-70^{\circ} \mathrm{C}$. The samples were then piperidine treated in parallel with the in vivo samples. For in vitro controls that were not reacted with DMS or piperidine, the DNA was first cleaved with $E c O R I$ and RNase A to reduce viscosity and remove contaminating RNA, respectively, and then processed in parallel with the other samples.

\section{In vivo and in vitro genomic DNase treatment}

Cells for in vivo DNase I footprinting were treated identically to those used for RNA measurements. Preparation of nuclei and in vivo DNase treatment was performed as described by Zinn and Maniatis (1985) with slight modifications. Naked DNA (in vitro) was prepared by the conditions described above, and digested with DNase I (Boehringer Mannheim Biochemicals) to the same extent as the nuclear samples/empirically determined). Underdigestion would show a general underrepresentation of lower-molecular-weight bands and overrepresentation of high-molecular-weight bands. The converse is true for overdigestion. Such mismatches in DNase I conditions do not, however, produce specific local patterns of protection that would be easily mistaken for protein : DNA footprints. Both the in vitro and the in vivo DNAs were also digested with EcoRI and RNase A to reduce viscosity and remove contaminating RNA.

\section{Primer extension of DMS and DNase-cleaved genomic DNA}

Visualizing the footprint patterns by primer extension eliminates the technically challenging blotting of sequencing gels and subsequent hybridization (Church and Gilbert 1984). In addition, extension of an end-labeled primer ensures that single base resolution is not compromised by either radioactive decay of a multiply end-labeled probe or imprecise action of a singlestranded nuclease (Jackson and Felsenfeld 1985). Because loading more than $\sim 75 \mu \mathrm{g}$ of DNA per lane (lane size 8 $\mathrm{mm} \times 0.8 \mathrm{~mm}$ ) leads to decreased resolution, our procedure required $\sim 15$ copies per mammalian genome (P. Mueller, un- publ.). Specifically, $65 \mu \mathrm{g}$ A-0.3 DNA or $14 \mu \mathrm{g}$ of A-60 DNA were mixed with 0.13 pmole labeled primer isp. act. $6-14 \times 10^{6} / \mathrm{pmole} /$ and suspended in $55 \%$ deionized formamide, $6 \times$ SSPE [ $900 \mathrm{~mm} \mathrm{NaCl}, 60 \mathrm{~mm} \mathrm{NaH} \mathrm{PO}_{4}: \mathrm{H}_{2} \mathrm{O}, 6 \mathrm{~mm}$ EDTA (pH 7.4)]; final volume was $70 \mu$ l. The primers used were complementary to -227 to -203 on the noncoding strand and to +47 to +23 on the coding strand. These 25 -mers have a GC content of $60 \%$ and $52 \%$, respectively. Samples were heated to $95^{\circ} \mathrm{C}$ for $5 \mathrm{~min}$ and incubated for $30-60 \mathrm{~min}$ at $30^{\circ} \mathrm{C}$. These conditions proved to maximize the amount of primer hybridized while minimizing the self-hybridization of the genomic DNA and nonspecific background hybridization of the primers (P. Mueller, unpubl.). Different length or GC content of the primers might require different hybridization conditions. To remove excess primer and change the reaction buffer, one of two methods was used. For the DNase and early DMS experiments, the hybridization mixture was run over a quick-spin column of Sephadex G-50 equilibrated in low KT buffer (12.5 $\mathrm{mM} \mathrm{KCl}, 12.5 \mathrm{mM}$ Tris, $\mathrm{pH} 8.3$ at $50^{\circ} \mathrm{C}$ ), and the volume of the efflux was adjusted to $87.5 \mu \mathrm{l}$ with low KT buffer. In other experiments, the hybridization mixture was diluted to a volume of $670 \mu \mathrm{l}$ with $2.25 \mathrm{M}$ ammonium acetate and then precipitated with isopropanol. The pelleted DNA was then dissolved in 87.5 $\mu l$ of low KT buffer. In either case the DNA was then mixed with $12.5 \mu 18 \times$ AMV reverse transcription buffer so that the final concentrations were $50 \mathrm{~mm} \mathrm{KCl}, 50 \mathrm{~mm}$ Tris, $\mathrm{pH} 8.3$ at $50^{\circ} \mathrm{C}, 8 \mathrm{mM} \mathrm{MgCl}_{2}, 0.8 \mathrm{mM} \mathrm{dNTP}$, and $4 \mathrm{~mm}$ DTT. Two microliters (28 units) AMV reverse transcriptase (Life Sciences, Inc.) were added and primers were extended for $30 \mathrm{~min}$ at $50^{\circ} \mathrm{C}$. The reaction was terminated by adding $3 \mu \mathrm{l} 500 \mathrm{~mm}$ EDTA, $35 \mu \mathrm{l} 8$ $\mathrm{M}$ ammonium acetate, and 10-20 $\mu \mathrm{g}$ yeast tRNA. Samples were precipitated with 1 volume isopropanol, suspended in 12 $\mu l$ loading buffer $[80 \%$ deionized formamide, $40 \mathrm{~mm}$ Tris-borate (pH 7.5)] and run on $8 \%$ denaturing polyacrylamide gels 0.8 mm thick. Gels were dried and exposed for 1-10 days without an intensifying screen.

\section{In vitro footprinting of SP1}

In vitro DNase I footprints were performed, as described by Briggs et al. (1986), with $95 \%$ homogeneous, human SP1 that was $\sim 10 \mathrm{ng} / \mathrm{ml}$ (a gift from J. Kadonaga and R. Tjian). The mouse 400-bp MT-I promoter fragment was labeled at the BamHI site of plasmid MT-I $\Delta \mathrm{i}$ (a gift from R. Palmiter), and the SV40 326 bp promoter fragment was labeled at the HindIII site of plasmid SV2-DHFR (Southern and Berg 1982); 6.5 fmoles of each of these end-labeled DNA fragments were used and 8 $\mathrm{ng} / \mathrm{ml}$ was the final DNase I concentration (Boehringer Mannheim Biochemicals|. Gels were run as above.

\section{Quantitation of DMS footprints}

Several exposures of footprinting gels were prepared using Kodak XAR-5 film without an intensifying screen. Densitometry was performed with a LKB UltroScan XL laser densitometer, which has a beam size of $800 \mu \mathrm{m}$ by $50 \mu \mathrm{m}$. Each lane was scanned nine times with a $200-\mu \mathrm{m}$ overlap between scans and a $120-\mu \mathrm{m}$ vertical step. These scans were analyzed using the Turbo-Densitometry program (S.J.S.). Averaging of the nine scans produced a single composite scan per lane. To compare the various lanes of each loading (i.e., naked, in vivo noninduced, and in vivo induced), the composite scans were aligned, and the signal normalized. This normalization was to sequences in the guanine ladder that lacked both binding sites and observable footprints; this compensated for minor variations in sample loading, and had only a slight effect $(\leqslant 10 \%)$ on the final quantitation of protection and hypersensitivity. To 
quantitate individual protections and hypersensitivities, the integrated area for each base in the original plots was subtracted from the corresponding area in the naked DNA plot, and the difference was divided by the area of the naked DNA base. Difference plots are useful for illustrating footprints and comparing occupancy under noninduced and induced conditions. These were obtained by subtracting the digitized and normalized scan of one lane from that of another lane on a point-bypoint basis. These plots indicate regions of protection above the baseline and regions of hypersensitivity below the baseline.

\section{Acknowledgments}

The authors with to thank Drs. R. Palmiter and R. Schimke for supplying DNAs used in plasmid constructions, R. Tjian and J. Kadonaga for purified SP1 factor, and J. Huibregtse and D. Engelke for communicating results before publication. We thank Prof. Peter Dervan for use of the scanning densitometer; Jan Hoh, J. Daniels, and Dr. John Ngai for helpful discussion; and Profs. David Anderson, Norman Davidson, Mel Simon, and members of the Wold group for interesting discussions and critical reading of the manuscript. This work was supported by grants from the Rita Allen Foundaton and the National Institutes of Health to B.W., a National Research Services Award (1 T32 GM 07616) from the National Institute of General Medical Sciences to P.R.M., and a California Institute of Technology SURF Fellowship to S.J.S.

\section{References}

Anderson, R.D., B.W. Birren, S.J. Taplitz, and H.R. Herschman. 1986. Rat metallothionein-I structural gene and three pseudogenes, one of which containing 5 '-regulatory sequences. Mol. Cell. Biol. 6: 302-314.

Andersen, R.D., S.J. Taplitz, S. Wong, G. Bristol, B. Larkin, and H.R. Herschman. 1987. Metal-dependent binding of a factor in vivo to the metal-responsive elements of the metallothionein I gene promoter. Mol. Cell. Biol. 7: 3574-3581.

Angel, P., M. Imagawa, R. Chiu, B. Stein, R.J. Imbra, H.J. Rahmsdorf, C. Jonat, P. Herrlich, and M. Karin. 1987. Phorbol ester-inducible genes contain a common cis element recognized by a TPA-modulated trans-acting factor. Cell 49: 729-739.

Angel, P., A. Poting, U. Mallick, H.J. Rahmsdorf, M. Schorrp, and P. Herrlich. 1986. Induction of metallothionein and other mRNA species by carcinogens and tumor promoters in primary human skin fibroblast. Mol. Cell. Biol. 6: 17601766.

Briggs, M.R., J.T. Kadonaga, S.P. Bell, and R. Tjian. 1986. Purification and biochemical characterization of the promoterspecific transcription factor, SP1. Science 234: 47-52.

Brinster, R.L., H.Y. Chen, R. Warren, A. Sarthy, and R.D. Palmiter. 1982. Regulation of metallothionein-thymidine kinase fusion plasmids injected into mouse eggs. Nature 296: $39-42$.

Buchanan, R.L. and J.D. Gralla. 1987. Factor interactions at simian virus $40 \mathrm{GC}$-box promoter elements in intact nuclei. Mol. Cell. Biol. 7: 1554-1558.

Carter, A.D., B.K. Felber, M. Walling, M.F. Jubier, C.J. Schmidt, and D.H. Hamer. 1984. Duplicated heavy metal control sequences of the mouse metallothionein gene. Proc. Natl. Acad. Sci. 81: 7392-7396.

Carthew, R.W., L.A. Chodosh, and P.A. Sharp. 1985. An RNA polymerase II transcription factor binds to an upstream element in the adenovirus major late promoter. Cell 43: 439448.
1987. The major late transcription factor binds to and activates the mouse metallothionein I promoter. Genes Dev. 1: 973-980.

Chirgwin, J.M., A.E. Przybyla, R.J. MacDonald, and W.J. Rutter. 1979. Isolation of biologically active ribonuclei acid from sources enriched in ribonuclease. Biochemistry 18: 52945299.

Chodosh, L.A., R.W. Carthew, and P.A. Sharp. 1986. A single polypeptide possesses the binding and transcription activities of the adenovirus major late transcription factor. Mol. Cell. Biol. 6: 4723-4733.

Church, G.M. and W. Gilbert. 1984. Genomic sequencing. Proc. Nat1. Acad. Sci. 81: 1991-1995.

Davison, B.L., J.M. Egly, E.R. Mulvihill, and P. Chambon. 1983. Formation of stable preinitiation complexes between eukaryotic class B transcription factors and promoter sequences. Nature 301: 680-686.

Durnam, D.M. and R.D. Palmiter. 1981. Transcriptional regulation of the mouse metallothionein-I gene by heavy metals. $J$. Biol. Chem. 256: 5712-5716.

Dynan, W.S. and R. Tjian. 1985. Control of eukaryotic messenger RNA synthesis by sequence-specific DNA-binding proteins. Nature 316: 774-778.

Ephrussi, A., G.M. Church, S. Tonegawa, and W. Gilbert. 1985. B Lineage-specific interactions of an immunoglobulin enhancer with cellular factors in vivo. Science 227: 134-140.

Farnham, P.J. and R.T. Schimke. 1986. In vitro transcription and delimitation of promoter elements of the murine dihydrofolate gene. Mol. Cell. Biol. 6: 2392-2401.

Gidoni, D., J.T. Kadonaga, H. Barrera-Saldana, K. Takahashi, P. Chambon, and R. Tjian. 1985. Bidirectional SV40 transcription mediated by tandem SP1 binding interactions. Science 230: $511-517$.

Gidoni, D. W.S. Dynan, and R. Tjian. 1984. Multiple specific contacts between a mammalian transcription factor and its cognate promoters. Nature 312: 409-413.

Gilbert, W., A. Maxam, and A. Mirzabekov. 1976. Contacts between the LAC repressor and DNA revealed by methylation. In Control of ribosome synthesis, Alfred Benzon Symposium IX (ed. N.O. Kjeldgaard and O. Maaloe), pp. 139-148. Academic Press, New York.

Gimble, J.M. and E.E. Max. 1987. Human immunoglobulin kgene enhancer: Chromatin structure analysis at high resolution. Mol. Cell. Biol. 7: 15-25.

Giniger, E., S.M. Varnum, and M. Ptashne. 1985. Specific DNA binding of GAL4, a positive regulatory protein of yeast. Cell 40: $767-774$.

Glanville, N., D.M. Durnam, and R.D. Palmiter. 1981. Structure of mouse metallothionein-I gene and its mRNA. Nature 292: 267-269.

Groudine, M., M. Peretz, and H. Weintraub. 1981. Transcriptional regulation of hemoglobin switching in chicken embryos. Mol. Cell. Biol. 1: 281-288.

Hamer, D.H. 1986. Metallothionein. Annu. Rev. Biochem. 55: 913-951.

Hamer, D.H. and M. Walling. 1982. Regulation in vivo of a cloned mammalian gene: Cadmium induced the transcription of a mouse metallothionein gene in SV40 vectors. $J$. Mol. Appl. Genet. 1: 273-288.

Heguy, A., A West, R.I. Richards, and M. Karin. 1986. Structure and tissue-specific expression of the human metallothionein $\mathrm{I}_{\mathrm{B}}$ gene. Mol. Cell. Biol. 6: 2149-2157.

Huibregtse, J.M. and D.R. Engelke. 1986. Direct identification of small sequence changes in chromosomal DNA. Gene 44: 151-158.

Imbra, R.J. and M. Karin. 1987. Metallothionein gene expres- 
sion is regulated by serum factors and activators of protein kinase C. Mol. Cell. Biol. 7: 1358-1363.

Jackson, P.D. and G. Felsenfeld. 1985. A method for mapping intranuclear protein-DNA interactions and its application to a nuclease hypersensitive site. Proc. Natl. Acad. Sci. 82: $2296-2300$.

- 1987. In vivo footprinting of specific protein-DNA interactions. In Methods enzymol. (ed. S. Berger and A.R. Kimmel), vol. 152, pp. 735-755. Academic Press, New York.

Johnsrud, L. 1978. Contacts between Escherichia coli RNA polymerase and a lac operon promoter. Proc. Natl. Acad. Sci. 75: 5314-5318.

Jones, K.A. and R. Tjian. 1985. Spl binds to promoter sequences and activates herpes simplex virus 'immediate-early' gene transcription in vitro. Nature 317: 179-182.

Jones, K.A., J.T. Kadonaga, P.A. Luciw, R. Tjian. 1986. Activation of the AIDS retrovirus promoter by the cellular transcription factor, Spl. Science 232: 755-759.

Kadonaga, J.T., K.A. Jones, and R. Tiian. 1986. Promoter-specific activation of RNA polymerase II transcription by Spl Trends in Biochem. 11: 20-23.

Karin, M. 1985. Metallothioneins: Proteins in search of function. Cell 41: 9-10.

Karin, M., A. Haslinger, A. Heguy, T. Dietlin, and T. Cooke. 1987. Metal-responsive elements act as positive modulators of human metallothionein- $\mathrm{II}_{\mathrm{A}}$ enhancer activity. Mol. Cell. Biol. 7: 606-613.

Karin, M., A. Haslinger, H. Holtgreve, R.I. Richards, P. Krauter, H.M. Westphal, and M. Beato. 1984. Characterization of DNA sequences through which cadmium and glucocorticoid hormones induce human metallothionein- $\mathrm{II}_{\mathrm{A}}$ gene. $\mathrm{Na}$ ture 308: 513-519.

Karin, M. and H. Holtgreve. 1984. Nucleotide sequence requirements for transient expression of human metallothioneinIIA-thymidine kinase fusion genes. DNA 3: 319-326.

Karin, M. and R.I. Richards. 1982. Human metallothionein genes-primary structure of the metallothionein-II gene and a related processed gene. Nature 299: 797-802.

Kemper, B., P.D. Jackson, and G. Felsenfeld. 1987. Proteinbinding sites within the 5' DNase I-hypersensitive region of the chicken $\alpha^{\mathrm{D}}$-globin gene. Mol. Cell. Biol. 7: 2059-2069.

Kim, S.K. and B.J. Wold. 1985. Stable reduction of thymidine kinase activity in cells expressing high levels of anti-sense RNA. Cell 42: 129-138.

Lee, W., A. Haslinger, M. Karin, and R. Tjian. 1987a. Activation of transcription by two factors that bind promoter and enhancer sequences of the human metallothionein gene and SV40. Nature 325: 368-372.

Lee, W., P. Mitchell, and R. Tjian. 1987b. Purified transcription factor AP-1 interacts with TPA-inducible enhancer elements. Cell 49: 741-752.

Maniatis, T., S. Goodbourn, and J.A. Fischer. 1987. Regulation of inducible and tissue-specific gene expression. Science 236: $1237-1245$.

Maroni, G., E. Otto, and D. Lastowski-Perry. 1986. Molecular and cytogenetic characterization of a metallothionein gene of Drosophila. Genetics 112: 493-504.

Maxam, A.M. and W. Gilbert. 1980. Sequencing end-labeled DNA with base-specific chemical cleavages. In Methods enzymol. (ed. L. Grossman and K. Moldavel, vol. 65, pp. 499-560. Academic Press, New York.

Mayo, K.E., R. Warren, and R.D. Palmiter. 1982. The mouse metallothionein-I gene is transcriptionally regulated by cadmium following transfection into human or mouse cells. Cell 29: 99-108.
Mitchell, P.J., C. Wang, and R. Tjian. 1987. Positive and negative regulation of transcription in vitro: Enhancer-binding protein AP-2 is inhibited by SV40 T antigen. Cell 50: $847-$ 861.

Miyamoto, N.G., V. Moncollin, J.M. Egly, and P. Chambon. 1985. Specific interacton between a transcription factor and the upstream element of the adenovirus- 2 major late promoter. EMBO J. 4: 3563-3570.

Ngai, J., Y.G. Capetanaki, and E. Lazarides. 1984. Differentiation of murine erythroleukemia cells results in the rapid repression of vimentin gene expression. J. Cell. Biol. 99: 306314.

Palmiter, R.D., H.Y. Chen, and R.L. Brinster. 1982. Differential regulation of metallothionein-thymidine kinase fusion genes in transgenic mice and their offspring. Cell 29: 701710.

Parker, C.S. and J. Topol. 1984. A Drosophila RNA polymerase II transcription factor binds to the regulatory site of an hsp 70 gene. Cell 37: 273-283.

Pavlakis, G.N. and D.H. Hamer. 1983. Regulation of a metallothionein-growth hormone hybrid gene in bovine papilloma virus. Proc. Natl. Acad. Sci. 80: 397-401.

Richards, R.I., A. Heguy, and M. Karin. 1984. Structural and functional analysis of the human metallothionein- $\mathrm{I}_{\mathrm{A}}$ gene: Differential induction by metal ions and glucocorticoids. Cell 37: 263-272.

Sawadogo, M. and R.G. Roeder. 1985. Interaction of a gene-specific transcription factor with the Adenovirus major late promoter upstream of the TATA box region. Cell 43: 165175.

Schmidt, C.J., M.F. Jubier, and D.H. Hamer. 1985. Structure and expression of two human metallothionein-I isoform genes and a related pseudogene. J. Biol. Chem. 260: 7731-7737.

Scholer, H., A. Haslinger, A. Heguy, H. Holtgreve, and M. Karin. 1986. In vivo competition between a metallothionein regulatory element and the SV40 enhancer. Science 232: $76-80$.

Searle, P.F., B.L. Davison, G.W. Stuart, T.M. Wilkie, G. Norstedt, and R.D. Palmiter. 1984. Regulation, linkage, and sequence of mouse metallothionein I and II genes. Mol. Cell. Biol. 4: 1221-1230.

Searle, P.F., G.W. Stuart, and R.D. Palmiter. 1985. Building a metal-responsive promoter with synthetic regulatory elements. Mol. Cell. Biol. 5: 1480-1489.

Seguin, C. and D.H. Hamer. 1987. Regulation in vitro of metallothionein gene binding factors. Science 235: 1383-1387.

Seguin, C., B.K. Felber, A.D. Carter, and D.H. Hamer. 1984. Competition for cellular factors that activate metallothionein gene transcription. Nature 312: 781-785.

Southern, P.J. and P. Berg. 1982. Transformation of mammalian cells to antibiotic resistance with a bacterial gene under control of the SV40 early region promoter. I. Mol. Appl. Genet. 1: 327-341.

Stuart, G.W., P.F. Searle, and R.D. Palmiter. 1985. Identification of multiple metal regulatory elements in mouse metallothionein-I promoter by assaying synthetic sequences. $\mathrm{Na}$ ture 317: 828-831.

Stuart, G.W., P.F. Searle, H.Y. Chen, R.L. Brinster, and R.D. Palmiter. 1984. A 12-base-pair DNA motif that is repeated several times in metallothionein gene promoters confers metal regulation to a heterologous gene. Proc. Natl. Acad. Sci. 81: 7318-7322.

Varshney, U., N. Jahrousi, R. Foster, and L. Gedamu. 1986. Structure, organization, and regulation of human metallothionein IF gene: Differential and cell-type-specific expression 
in response to heavy metals and glucocorticoids. Mol. Cell. Biol. 6: 26-37.

Zinn, K. and T. Maniatis. 1986. Detection of factors that interact with the human $\beta$-interferon regulatory region in vivo by DNase I footprinting. Cell 45: 611-618.

Zinn, K., D. DiMaio, and T. Maniatis. 1983. Identification of two distinct regulatory regions adjacent to the human $\beta$-interferon gene. Cell 34: 865-879. 


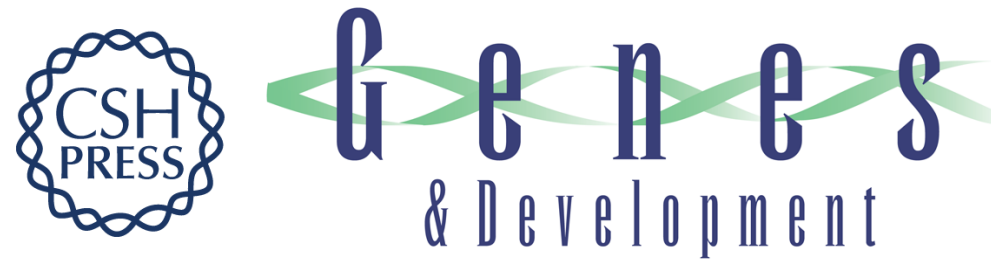

\section{Constitutive and metal-inducible protein:DNA interactions at the mouse metallothionein I promoter examined by in vivo and in vitro footprinting.}

P R Mueller, S J Salser and B Wold

Genes Dev. 1988, 2:

Access the most recent version at doi:10.1101/gad.2.4.412

References This article cites 63 articles, 31 of which can be accessed free at: http://genesdev.cshlp.org/content/2/4/412.full.html\#ref-list-1

License

Email Alerting Service

Receive free email alerts when new articles cite this article - sign up in the box at the top right corner of the article or click here.

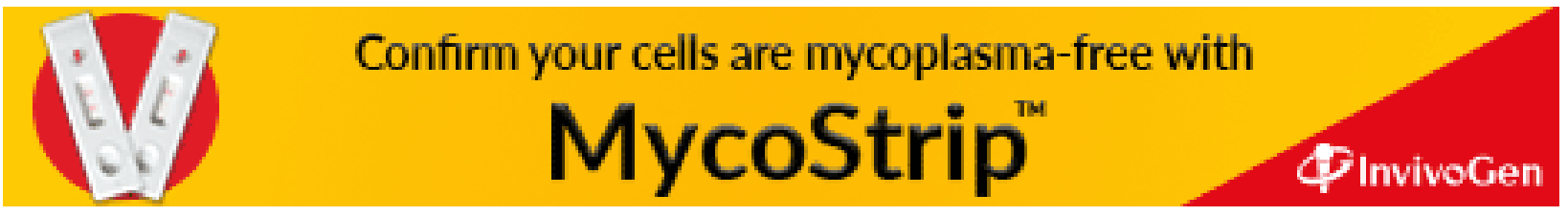

